\title{
The Systemic and Genetic Significance of Congenital Optic Disc Anomalies
}

\author{
M. JACOBS and D. TAYLOR \\ London
}

\begin{abstract}
Summary
Optic disc anomalies have great significance as a clue to associated systemic problems and as a marker of inherited disease. Optic nerve hypoplasia and colobomas of the optic disc are the main visually significant disorders; however, the Morning Glory disc anomaly and Aicardi's syndrome may also be associated with visual impairment.
\end{abstract}

The diagnosis of congenital optic disc anomalies is of great importance because of the genetic and systemic implications. The ophthalmologist has the opportunity of being the first to diagnose an underlying disease or syndrome and referring patients for genetic and paediatric assessment. It is of equal significance to parents that some optic nerve anomalies are not associated with inherited disease. Peripapillary myelinated nerve fibres and optic disc drusen which are not usually associated with systemic conditions are not discussed.

\section{Optic Nerve Hypoplasia}

Optic nerve hypoplasia is a unilateral or bilateral, non-progressive condition which results from an excessive loss of axons of the involved optic nerve before its full development. ${ }^{1.2}$

It is characterised by the presence of a small optic disc often surrounded by an inner yellow ring and an outer pigmented ring, which comprises the 'double ring sign' (Fig. 1). ${ }^{+}$The major blood vessels coming off the hypoplastic optic disc are usually normal although sometimes they may be tortuous. ' Only a part of the disc may be hypoplastic. Superior seg- mental optic nerve hypoplasia is thought to be associated with maternal diabetes. ${ }^{36}$

The visual acuity may vary from near normal (6/9) to no light perception. ${ }^{3}$ Severe optic nerve hypoplasia is easily appreciated but the more subtle forms are more difficult to diagnose even with direct ophthalmoscopy. ${ }^{5}$ Diagnosis is essentially clinical but the diagnosis may be aided by further studies. Firstly, diagnosis can be enhanced by comparing the ratio of the major blood vessel diameter to the diameter of the optic disc, and secondly by studying the ratio of the disc centre-to-fovea distance (DM) to disc diameter (DD) from a photograph (a DM/DD ratio of greater than 3 is considered diagnostic). Another method is by measuring the horizontal diameter of the optic disc from a $35 \mathrm{~mm}$ transparency; optic discs less than $3.4 \mathrm{~mm}$ in horizontal disc diameter can be considered hypoplastic in subjects with no major ametropia. ${ }^{6.7}$ Although not diagnostic the pattern and flash visual evoked potential may also be of assistance in that it may help to identify and quantify the postretinal defect in which the responses are attenuated; the electroretinogram is normal.

The cause of optic nerve hypoplasia is 


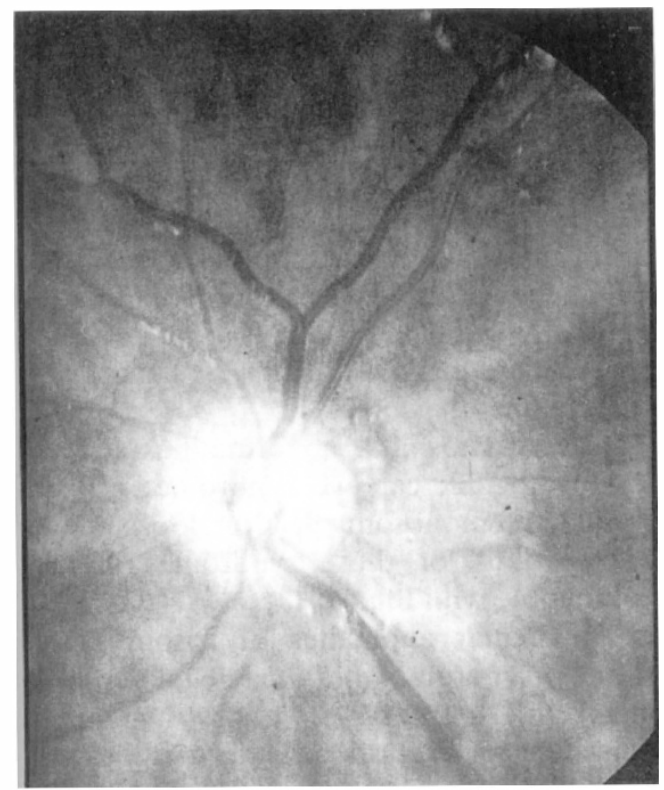

Fig. 1. Optic disc hypoplasia. The outer ring of the double ring is about the size of a normal optic disc

unknown. It may occur due to an insult anywhere along the developing visual system from the retinal ganglion cells to the occipital cortex.

Retrograde degeneration of axons which is a normal phenomenon in the developing optic nerve may be excessive resulting in reduced numbers of axons. ' Chromosomal studies in the vast majority of cases are normal. Siblings have been described with De Morsier's svndrome and there are a few reports of familial cases." Most geneticists consider the condition to be non-genetic with low recurrence risks in the absence of environmental causes. ${ }^{5}$ Optic nerve hypoplasia has been associated with diabetic mothers, young maternal age, nulliparity, intrauterine infections, and maternal ingestion of quinine, lysergic acid and diethylamide, alcohol and anticonvulsants. $1.5 .111+1+.50$

Ocular associations include microphthalmos, aniridia, coloboma, nystagmus and strabismus. ${ }^{2}$

There is a high incidence of neurological and endocrine associations." The neurological associations include basal encephalocoeles, hypoplasia of the cerebellar vermis, cystic dilatation of the thentricle, posterior fossa cysts, and anterior visual pathway space occupying lesions including tumours." "11.15
De Morsier's syndrome (septo-optic dysplasia) is recognised by the clinical triad of short stature, nystagmus and optic disc hypoplasia. "It is characterised by a spectrum of midline developmental anomalies associated with optic nerve hypoplasia and possible hypopituitarism. ${ }^{9.17-19}$ These midline developmental anomalies may involve the optic chiasm, optic tracts, the septum pellucidum. corpus callosum, 3rd ventricle, hypothalmus, pituitary stalk, and the pituitary gland. ${ }^{4.17-19}$ Other central nervous system abnormalities associated with this syndrome include cerebral and cerebellar atrophy, hydrocephalis, cerebral infarcts, and porencephalic cysts. ${ }^{31}$.11 About two-thirds of patients with De Morsier's syndrome are estimated to have some form of pituitary hypofunction..$^{21.22}$ The pituitary hypofunction varies from a deficiency of growth hormone to panhypopituitarism." The most common pituitary abnormality is that of growth hormone deficiency. ${ }^{23}$ During the neonatal period infants may present with hypoglycaemia, jaundice, apnoea or scizures.

It has been suggested that workup of these patients should include neuroradiologic imaging studies if the patients are below four years of age, but if normal developmental milestones are achieved after one year of age we believe that neuroradiologic studies are not necessarily helpful.' Magnetic resonance imaging rather than computerised tomography is probably the procedure of choice as the former is thought to be more sensitive for detecting subtle midline abnormalities. ${ }^{\text {IS }}$

Careful monitoring of growth and development is important in the management of these children and this applies also to unilateral cases." Children with unilateral optic nerve hypoplasia and reduced vision should undergo a trial of occlusion therapy because amblyopia may be added to the organic visual defect. ${ }^{11}$

\section{Colobomas of the optic nerve}

The term 'coloboma' describes a notch, gap or fissure in the eye..$^{2.2+}$ These occur secondary to faulty closure of the embryonic fissure. ${ }^{2+}$ Colobomas can be subdivided into two main types; chorioretinal (which may be associated with colobomas of the iris, ciliary body and 


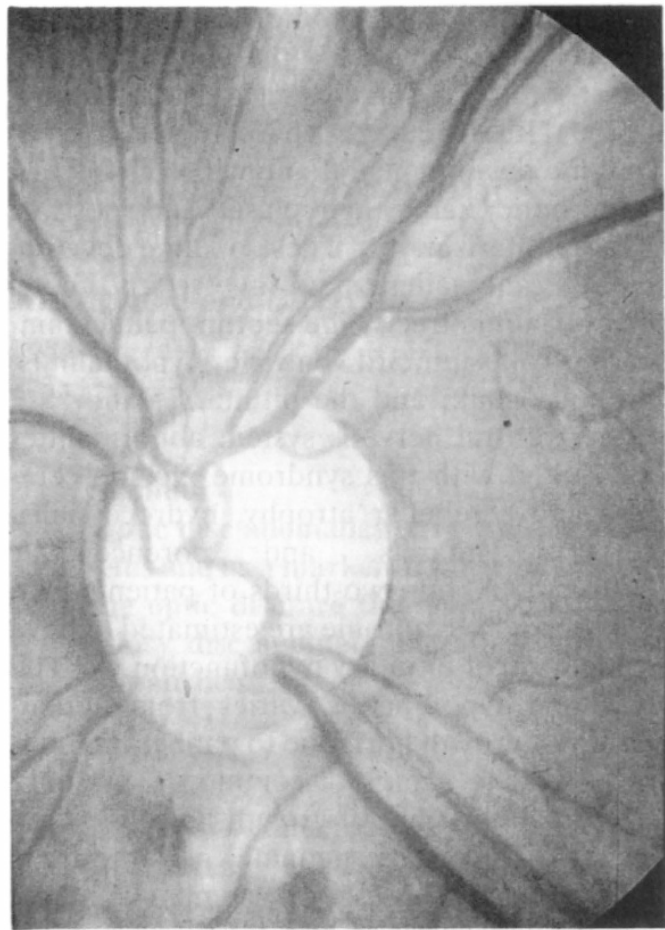

Fig. 2. Optic disc coloboma. The optic disc is enlarged with an excavated centre. This patient had assoiated renal and anal abnormalities.

optic disc colobomas) and optic nerve colobomas. ${ }^{2}$

Optic nerve colobomas are usually unilateral although bilateral colobomas are quite frequent but asymmetrical. ${ }^{25}$ Most are sporadic although an autosomal dominant hereditary pattern has been reported and less frequently autosomal recessive or $\mathrm{X}$-linked recessive pedigrees. ${ }^{25}$ Chromosomal analysis should be considered in children with optic disc colobomas.

Optic disc colobomas may appear as large excavations of the nerve head up to 25 dioptres deep and involving nearly all of the disc which may be enlarged (Fig. 2). ${ }^{25}$ The colobomas may assume different forms including optic disc pits, peripapillary staphylomas, and a variety of anomalous dysplastic forms. ${ }^{16}$ If the macula or optic nerve is involved then there may be a reduction in

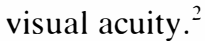

Optic disc colobomas may be associated with a variety of ocular anomalies including posterior embryotoxon, nonrhegmatogenous retinal detachment, strabismus, nystagmus and posterior lenticonus. ${ }^{2.25 .26}$

When associated with systemic problems they can be divided into four groups. ${ }^{2}$

(1) Neurological associations: Dandy Walker cyst, arhinencephaly, anencephaly, agenesis of the corpus callosum, and sphenoidal encephalocoeles. The morning glory disc anomaly (see below) may also be associated with some of the above neurological associations. ${ }^{37}$

(2) Chromosomal abnormalities: trisomy $13-15,18,22$; cat eye syndrome; 4p- syndrome and monosomy 9, 11p-, 13q- and triploidy. Many of these syndromes are not compatible with life.

The ocular anomalies of trisomy 13-15 (Patau's syndrome) may include microphthalmia, retinal dysplasia, optic nerve hypoplasia,

persistent hyperplastic primary vitteous, cât. aract, anterior cleavage syndrome. corneal opacities, cyclopia, intraocular cartilage and colobomas of the optic nerve, iris, and/or posterior pole. ${ }^{27.28}$ Other abnormalities include those of the heart and palate. ${ }^{2 *}$

Trisomy 18 (Edward's syndrome) may have any of the following ocular characteristics present: microphthalmia, prominent epicanthic folds, blepharophimosis, ptosis, hypertelorism, optic disc anomalies, uveal colobomas, congenital glaucoma, and corneal opacities. ${ }^{27}$ Affected infants are feeble with characteristic facies, mental retardation and cardiac abnormalities. ${ }^{29}$

(3) Syndromes: Meckel-Gruber syndrome (autosomal recessive), Goltz syndrome (X-

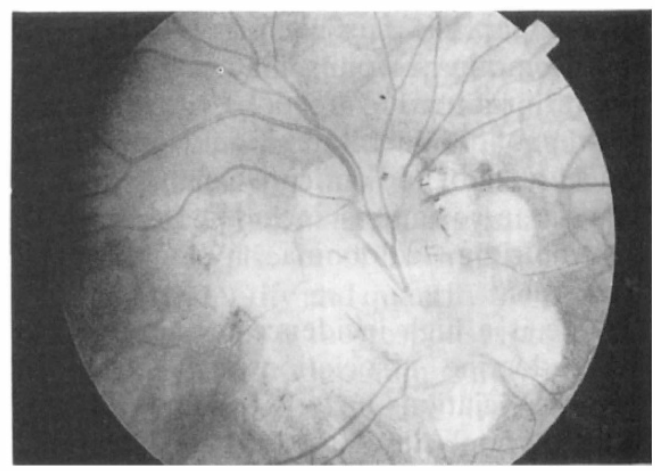

Fig. 3. Aicardi's syndrome. The right eye demonstrates peripapillary hypopigmented lacunae. The eye was also microphthalmic. 


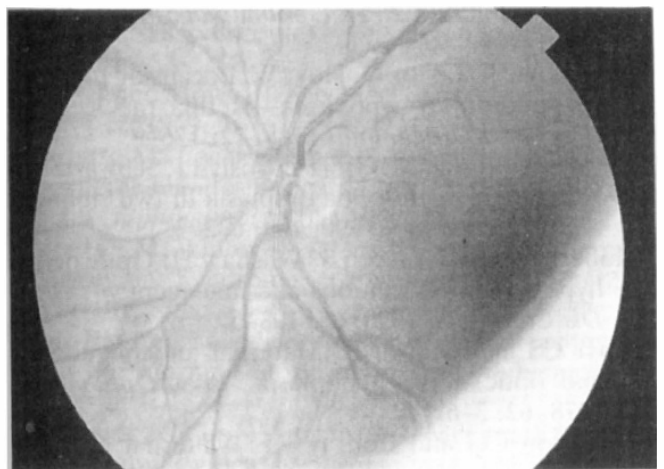

Fig. 4. Aicardi's syndrome. The left eve of the same patient as in Figure 4. The lacunae are less obvious but are present below the optic disc. The eye was of normal size.

linked dominant) and the Lenz Microphthalmia (X-linked recessive) syndrome.

The Meckèl-Gruber syndrome is an autosomal recessive condition characterised by coloboma, microphthalmos, cleft palate, micrognathia, polydactyly, renal abnormalities, encephalocoele and cryptorchidism. ${ }^{30}$

The Goltz syndrome is an X-linked dominant condition characterised by colobomas, focal dermal hypoplasia, and variable mental retardation.

The Lenz Microphthalmia syndrome is an $\mathrm{X}$-linked recessive condition characterised by colobomas, prominent ears, skeletal defects, and crowded teeth. ${ }^{32}$

(4) CHARGE association.

The CHARGE association includes patients with at least four features prefixed by the letters of the CHARGE mnemonic: Coloboma, Heart defects, Atresia of the choanae, Retarded growth and development, Genital hypoplasia. Ear abnormalities and/or hearing loss. ${ }^{26}$ Facial palsy, renal abnormalities, tracheo-oesophageal fistulae, and orofacial clefts may also accompany the above main features. ${ }^{26}$ Russell-Eggitt et al. found that $86 \%$ of patients with the CHARGE association had ocular abnormalities. ${ }^{26}$ They reported that the majority had retinochoroidal colobomata with optic nerve involvement. Some of the changes were subtle with sometimes only pallor of the retinal pigment epithelium inferonasal to the optic disc. ${ }^{26}$

The Morning Glory Anomaly

The morning glory disc anomaly is charac- terised by an enlarged and often excavated optic disc with a central core of white glial tissue and surrounded by a pigmented raised annulus of subretinal tissue (Fig. 5) $;^{37}$ however, it may have slightly varying configurations. ${ }^{37}$ The majority of the cases are unilateral. ${ }^{37}$ Visual acuity is generally poor (6/36 to light perception) but rarely may be good. ${ }^{38}$

Patients usually present with strabismus or poor vision in one eye. ${ }^{37} \mathrm{Up}$ to one-third of cases develop serous retinal detachment. ${ }^{33} \mathrm{It}$ may be associated with a host of other ocular anomalies including cataract, strabismus, foveal hypoplasia, preretinal gliosis, pupillary membrane remnants and aniridia to name a few. ${ }^{37}$ Systemic abnormalities that it may be associated with include basal encephalocoele, absent corpus callosum, cleft lip and palate.

and renal abnormalities but most eases oceur in isolation. ${ }^{37}$ Excavation results from a mesenchymal defect. ${ }^{3+}$ Either there is faulty closure of the posterior scleral wall and lamina cribrosa with subsequent herniation of ret-

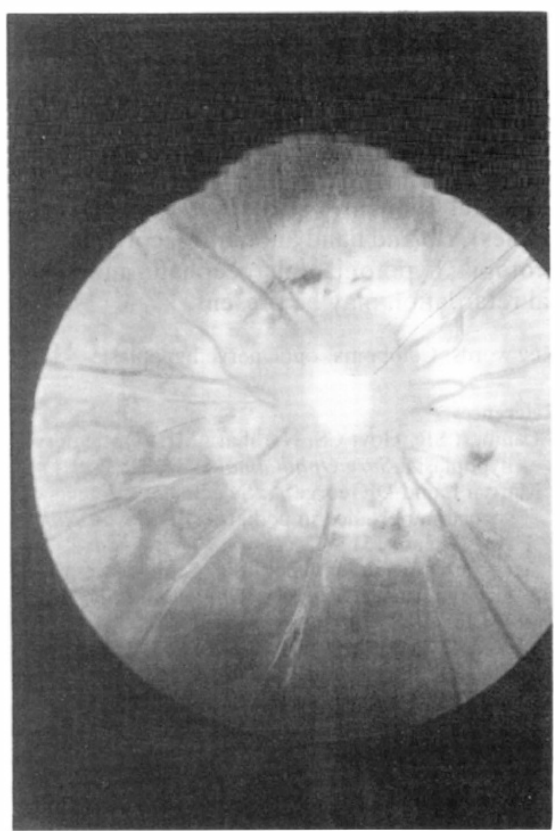

Fig. 5. The Morning Glory Disc Anomaly. This is an enlarged optic disc with raised peripapillary tissue and glial tissue in the centre of the concavity of the optic disc. 
inal and neural tissue, or perhaps there is a closure defect of the embryonic fissue..$^{3+.37}$

\section{Aicardi's syndrome}

This syndrome is characterised by infantile spasms, absence of the corpus callosum and defects in the choroid. ${ }^{35}$ It is nonfamilial and occurs in persons with two $\mathrm{X}$ chromosomes.

The choroidal lacunae are usually bilateral. ${ }^{35}$ Clinically they are well defined hypopigmented lesions with minimal surrounding pigment, and tend to occur around the optic disc (Figs 3 and 4). They appear to be a defect in the retinal pigment epithelium and choroid without significant retinal involvement. ${ }^{35}$ Adjacent to the disc there may be an elevated glial anomaly with grey pigmentation..$^{35}$

In three of four cases described by Hoyt $e t$ al. associated optic nerve colobomas were present. ${ }^{35}$ Other ocular features which may be present include microphthalmos, persistent pupillary membranes, and glial tissue extending from the optic disc. ${ }^{35}$

The seizures usually occur within the first two months of life; they may occur as infantile spasms or seizures of a more generalised disorder. ${ }^{41}$ The infantile spasms occur in flexion but may also occur in extension. ${ }^{35}$

Other than agenesis of the corpus callosum, vertebral anomalies (fusion of the vertebral bodies), rib and hand anomalies, cortical heterotopia, hypotonia, microcephalia and mental retardation may be present. ${ }^{39.40}$

Key words: Coloboma, optic nerve hypoplasia.

\section{References}

'Lambert SR, Hoyt CS, Narahara MH: Optic nerve hypoplasia. Surv Ophthalmol 1987, 32; 1-9.

${ }^{2}$ Martyn L and DiGeorge A: Selected eyc defects of special importance in pediatrics. Ped Clin North Am 1987, 6: 1517-42.

${ }^{3}$ Acers T: Optic nerve hypoplasia. Septo-optic-pituitary syndrome. Trans Am Ophthalmol Soc 1981. 79: $425-57$.

${ }^{4}$ Walton D and Robb M: Optic nerve hypoplasia. Arch Ophthalmol 1970, 84: 572-8.

${ }^{5}$ Hoyt C and Billson F: Optic nerve hypoplasia: changing perspectives. Austr NZ J Ophthalmol 1986, 14: 325-31.

'Romano PE: Simple photogammetric diagnosis of optic nerve hypoplasia. Arch Ophthalmol 1989. 107: 824-26.

'Alvarez E. Wakakura M, Kahn Z, Dutton G: The disc-macula distance to disc diameter ratio: a new test for confirming optic nerve hypoplasia in young children. J Ped Ophthalmol Strab 1988, 25 (3): $151-4$.

${ }^{x}$ Novakovic P, Taylor D. Hoyt W: Localising patterns of optic nerve hypoplasia-Retina to Occipital lobe. Br J Ophthalmol 1988, 72: 176-9.

${ }^{4}$ Benner J. Preslan M, Gratz E. Joslyn J, Schwartz M. Kelman S: Septo-optic dysplasia in two siblings. Am J Ophthalmol 1990, 109: 632-7.

"1"Roberts-Harry J, Green S, Wilshaw H: Optic nerve hypoplasia: associations and management. Arch Dis Childhood 199(), 65: 103-6.

${ }^{11}$ Hoyt CS and Billson F: Maternal anticonvulsants and optic nerve hypoplasia. Br J Ophthalmol 1978. 62: 3-6.

12 Robinson CG and Conray RF: Maternal age and congenital optic nerve hypoplasia: a possible clue to aetiology. Child Neurol 1986, 28:294-8.

1.3 Miller M. Israel J, Cuttone J: Fetal Alcohol Syndrome. J Ped Ophthalmol Strabis 1984, 55: 595-8.

${ }^{1+}$ Hoyt CS: Optic disc anomalies and maternal ingestion of LSD. I Ped Ophthalmol Strabis 1978, 15: 286-9.

Is Taylor D: Congenital tumours of the anterior visual system with dysplasia of the optic discs. $\mathrm{Br} J \mathrm{Oph}$ thalmol 1982, 66: 45.5-63.

"Glaser J: Topical diagnosis: Prechiasmal visual pathways. Duane's Clinical Ophthalmology. JB Lippincott Co. Revised Edition 1989. Vol 2; Chp 5.

- De Morsier G: Median cranioencephalic dysraphias and olfactogenital dysplasia. World Neurol 1962, 3: 485.

Kaufman L. Miller M. Mafee M: Magnetic resonance imaging of pituitary stalk hypoplasia. Arch Ophthalmol 1989, 107: 1485-9.

"Margalith D, Jun Tze W, Jan J: Congenital optic nerve hypoplasia with hypothalamic-pituitary dysplasia. Am J Dis Child 1985, 139: 361-6.

"Kaplan S. Grumbach M. Hoyt W: A svndrome of hypopituitary dwarfism. hypoplasia of optic nerves and malformation of prosencephalon. Pediatr Res 1970, 4: 48()-1.

${ }^{2}$ Hoyt W, Kaplan J, Grumbach M, Glaser J: Septooptic dysplasia and pituitary dwarfism. Lancet 1970, 1:893-4.

"- Costin G and Murphee A: Hypothalmic-pituitary function in children with optic nerve hypoplasia. Am J Dis Child 1985, 139: 249-54.

23 Arslanian S, Rothus W, Foley T, Becker D: Hormonal, metabolic and neuroradiologic abnormalities associated with septo-optic dysplasia. Acta Endocrinol 1984, 107: 282-4.

${ }^{24}$ Brown G: Congenital fundus abnormalities. Duane's Clinical Ophthalmology. JB Lippincott Co. Revised Edition 1989. Vol 3; Chp 8

25 Savell J and Cook J: Optic nerve colobomas of autosomal dominant heredity. Arch Ophthalmol 1976. 943: 395-7.

20 Russell-Eggitt I, Blake K, Taylor D, Wyse R: The cye in the CHARGE association. Br J Ophthalmol 1990, 74: 421-6.

2 Mets M: The eye and the chromosome. Duane's Clinical Ophthalmology. JB Lippincott Co. Revised Edition 1989. Vol 5: Chp 35.

${ }^{2 \times}$ Hocpner $\mathrm{J}$ and Yanoff $\mathrm{M}$ : Ocular anomalies in trisomy 13-15. Am J Ophthalmol 1972, 74: 729-37. 
${ }^{29}$ Mullaney J: Ocular malformations in trisomy 18 (Edward's syndrome). Am J Ophthalmol 1973. 76: $246-54$.

${ }^{3(1)}$ Opitz J and Howe J: The Meckel Syndrome. Birth Defects 1969. 5: 167-79.

${ }^{31}$ Warburg M: Focal Dermal Hypoplasia: ocular and general manifestations with a literature survey. Acta Ophthalmol (Kbh) 197(). 48: 525-36.

${ }^{32}$ Baraitser M. Winter R. Taylor D: The Lenz Microphthalmia Syndrome. Clin Genetics 1982, 22: 99-101.

${ }^{33}$ Haik B. Greenstein S. Smith M: Retinal detachment in the morning glory anomaly. Ophthalmology 1984. 91: 16.38-17.

${ }^{34}$ Dempster A. Lee W. Forrester J. McCreath G: The "morning glory syndrome"-A mesodermal defect"? Ophthalmologica 1983, 187: 222-30.

${ }^{35}$ Hoyt C. Billson F. Ouvrier R. Wise G: Ocular features of Aicardis syndrome. Arch Ophthalmol 1978. 96: 291-5.
"Kim R. Hoyt W. Lessell S. Narahara M: Superior segmental optic hypoplasia. A sign of maternal diabetes. Arch Ophthalmol 1989, 107: 1312-15.

:Traboulsi $\mathrm{M}$ and $\mathrm{O}^{-}$Neill $\mathrm{J}$ : The spectrum in the morphology of the so-called "Morning Glory. Disc Anomaly". J Ped Ophthalmol Strabis 1988. 25 (2): 92-8.

"Hamada S. Inoue Y. Matsuda K: A case of morning glory syndrome with good visual acuity. Jpn J Ophthalmol 1978, 32: 196-7.

"Dennis J and Bower B: The Aicardi syndrome. Dev Med Child Neurol 1970, 14: 382-90.

${ }^{40}$ De Jong J. Delleman J, Houben M: Agenesis of the corpus callosum, infantile spasms, ocular anomalies (Aicardi’s syndrome). Neurology 1976. 26: $1152-8$.

${ }^{+1}$ Aicardi J, Lefébvre J, Lérique-Loechlin A: A new syndrome: Spasm in flexion, callosal agenesis, ocular abnormalities. Electroencephalogr Clin Neurophysiol 1965, 19: 609-10. 